\title{
Role and Origin of the GABAergic Innervation of Dorsal Raphe Serotonergic Neurons
}

\author{
Damien Gervasoni, ${ }^{1}$ Christelle Peyron, ${ }^{1}$ Claire Rampon,, ${ }^{1}$ Bruno Barbagli, ${ }^{1}$ Guy Chouvet, ${ }^{2}$ Nadia Urbain, ${ }^{2}$ \\ Patrice Fort, ${ }^{1}$ and Pierre-Hervé Luppi ${ }^{1}$ \\ 1/nstitut National de la Santé et de la Recherche Médicale (INSERM) U480, 2INSERM U512, Université Claude Bernard \\ Lyon I, 69373 Lyon cedex 08, France
}

\begin{abstract}
Extracellular electrophysiological recordings in freely moving cats have shown that serotonergic neurons from the dorsal raphe nucleus (DRN) fire tonically during wakefulness, decrease their activity during slow wave sleep (SWS), and are nearly quiescent during paradoxical sleep (PS). The mechanisms at the origin of the modulation of activity of these neurons are still unknown. Here, we show in the unanesthetized rat that the iontophoretic application of the $\mathrm{GABA}_{\mathrm{A}}$ antagonist bicuculline on dorsal raphe serotonergic neurons induces a tonic discharge during SWS and PS and an increase of discharge rate during quiet waking. These data strongly suggest that an increase of a GABAergic inhibitory tone present during wakefulness is responsible for the decrease of activity of the dorsal raphe sero-
\end{abstract}

In the mammalian CNS, most of the serotonergic neurons are found within the dorsal raphe nucleus (DRN) (Dahlström and Fuxe, 1964). By means of their widespread projections throughout the entire brain, these neurons are thought to play a crucial role in various physiological and behavioral functions, including sleep (Jouvet, 1972; Jacobs et al., 1990; Jacobs and Azmitia, 1992). Accordingly, extracellular electrophysiological recordings in freely moving cats have shown that DRN serotonergic neurons fire tonically during wakefulness (W), decrease their activity during slow wave sleep (SWS), and are nearly quiescent during paradoxical sleep (PS) (PS-off cells) (McGinty and Harper, 1976; Trulson and Jacobs, 1979). The decrease of activity of these neurons during SWS or PS could be caused by a tonic GABAergic inhibition. Indeed, it has been shown that GABA-immunoreactive terminals contact serotonin-positive neurons in the rat DRN (Wang et al., 1992) that also express $\mathrm{GABA}_{\mathrm{A}}$ receptors (Gao et al., 1993). Moreover, iontophoretic application of GABA in anesthetized rats strongly inhibits DRN serotonergic neurons, and co-iontophoresis of the $\mathrm{GABA}_{\mathrm{A}}$ antagonists bicuculline or picrotoxin antagonizes this effect (Gallager and Aghajanian, 1976; Gallager, 1978). Furthermore, GABA-mediated IPSPs observed in vitro in DRN serotonergic cells using focal stimulation are

\footnotetext{
Received Aug. 8, 1999; revised March 20, 2000; accepted March 20, 2000.

This work was supported by Institut National de la Santé et de la Recherche Médicale (U480), Centre National de la Recherche Scientifique (ERS 5645), Université Claude Bernard Lyon I, and the 1996 European Sleep Research SocietySynthélabo European Research Grant. We thank C. Guillemort (GFG Co., PierreBénite, France) for his help in designing the head-restraining system, and G. Debilly and F. Lorent for their expert assistance in statistical analysis.

D.G. and C.P. contributed equally to this work.

Correspondence should be addressed to Dr. Damien Gervasoni, INSERM U480, Faculté de Médecine, 8 Avenue Rockefeller, 69373 Lyon cedex 08, France. E-mail: gervasoni@sommeil.univ-lyon1.fr.

Copyright (C) 2000 Society for Neuroscience $0270-6474 / 00 / 204217-09 \$ 15.00 / 0$
}

tonergic cells during slow wave and paradoxical sleep. In addition, by combining retrograde tracing with cholera toxin $\mathrm{B}$ subunit and glutamic acid decarboxylase immunohistochemistry, we demonstrate that the GABAergic innervation of the dorsal raphe nucleus arises from multiple distant sources and not only from interneurons as classically accepted. Among these afferents, GABAergic neurons located in the lateral preoptic area and the pontine ventral periaqueductal gray including the DRN itself could be responsible for the reduction of activity of the serotonergic neurons of the dorsal raphe nucleus during slow wave and paradoxical sleep, respectively.

Key words: dorsal raphe; GABA; serotonin; single-unit recordings; retrograde tracing; sleep-waking blocked by bicuculline applications (Pan and Williams, 1989). In addition, Levine and Jacobs (1992) showed in cats that the iontophoretic application of bicuculline reverses the typical suppression of DRN serotonergic neurons activity seen during SWS but has no effect on maintained activity during $\mathrm{W}$ and the suppression of activity occurring during PS. More recently, Nitz and Siegel (1997) in cats using the in vivo microdialysis technique found that GABA levels are similar during $\mathrm{W}$ and SWS and that PS is accompanied by a selective increase in GABA release. To explain the discrepancies between the two studies, Nitz and Siegel (1997) hypothesized that (1) a small increase in GABA release, possibly beyond the resolution of the microdialysis technique, might be sufficient to reduce DRN unit discharge during SWS and (2) the inability of iontophoresed bicuculline to reverse PS cessation of DRN unit discharge could be caused by incomplete antagonism of DRN GABA $A_{A}$ receptors as a result of increased GABA release. Therefore, to determine whether GABA plays a role in the decrease of activity of serotonergic cells of the DRN during SWS and PS, we tested in unanesthetized rats the effect of iontophoretic applications of bicuculline on these neurons during SWS, PS, and W. Furthermore, to localize candidate GABAergic neurons potentially responsible for the inhibitions found, we then combined injections of the retrograde tracer cholera-toxin B subunit $(\mathrm{CTb})$ in the DRN with the immunohistochemistry of glutamic acid decarboxylase (GAD, GABA enzyme of synthesis).

\section{MATERIALS AND METHODS}

Electrophysiology

Fixation of the head-restraining system. The procedure used has been described previously (Darracq et al., 1996; Gervasoni et al., 1998). Male Sprague Dawley rats (280-320 gm, $n=15$; IFFA Credo) were anesthetized with pentobarbital ( $45 \mathrm{mg} / \mathrm{kg}$, i.p.) and mounted conventionally in a stereotaxic frame (David Kopf), i.e., with ears and nose bars. The bone 
was exposed and cleaned. The skull was placed at a $15^{\circ}$ angle (nose tilted down) to spare the transverse sinus overlying the DRN during the subsequent electrode penetrations. Three stainless steel screws were fixed in the parietal and frontal parts of the skull and three steel electrodes were inserted into the neck muscles to monitor the electroencephalogram (EEG) and the electromyogram (EMG), respectively. The bone was then covered with a thin layer of acrylic cement (Superbond, Sun Medical Co.), except the region overlying the DRN and the lambdoid suture. At this time, the head-restraining system was put in place. It consists of a "U"-shaped piece of aluminum with four bolts in each angle cemented to the skull of the rat that can be easily fixed to a flexible carriage, itself fastened to a commercial stereotaxic apparatus with dummy ear bars. This device allows a painless stereotaxic restraint with a high mechanical stability. The $\mathrm{U}$ piece fixed to the carriage with four nuts was centered above the DRN entry region and embedded in a mount of dental cement with the EEG screws and wires and their six-pin connector. After the dental cement dried out, the four bolts were then unscrewed from the U, now firmly jointed to the rat's skull. The animal was removed from the stereotaxic apparatus and allowed to recover from surgery and anesthesia during a period of $48 \mathrm{hr}$, before the habituation began. The head restraining system ( $5 \mathrm{gm}$ weight) was well tolerated by the rats that were able to feed and drink normally.

Training and habituation. During 8-10 successive days, repetitive trials of increasing duration were performed to well habituate the rats to the restraining and recording systems. The rat was comfortably supported by a hammock with the head painlessly secured to the restraining frame. At the end of the training period, the rat could stay calm for periods of 5-7 hr during which quiet W, SWS, and PS could be observed. The day before the first recording session, under pentobarbital anesthesia, a $4 \mathrm{~mm}$ hole was made above the DRN and the dura was removed under microscopic control. The brain surface was cleaned at the beginning of each daily recording session under local lidocaine anesthesia. All animals were housed and cared for according to the National Institutes of Health (NIH) Guide for the Care and Use of Laboratory Animals (NIH Publication 80-23). The protocol of this study has been approved by our local ethical committee and the French Ministry of Agriculture (Authorization 03-505), and efforts were made to reduce the number of animals used.

Polygraphic recordings. Vigilance states were discriminated with the cortical EEG and neck EMG. During W, desynchronized (or activated) low-amplitude EEG was accompanied by a sustained EMG activity with phasic bursts (twitches). SWS was clearly distinguished by high-voltage slow waves $(1.5-4.0 \mathrm{~Hz})$ and spindles $(10-14 \mathrm{~Hz})$ and disappearance of phasic muscular activity in an immobile animal with closed eyes. A decrease in the EEG amplitude associated with a flat EMG (i.e., muscle atonia) signaled the onset of PS episodes further characterized by a pronounced theta rhythm $(5-9 \mathrm{~Hz})$. For each vigilance state, a spectral analysis of the EEG was made on-line using the Fast-Fourier Transform.

Micropharmacology. Extracellular recordings from individual DRN neurons were obtained with glass microelectrodes (3-5 $\mu \mathrm{m}$ tip diameter, 10-20 M $\Omega$, impedance measured at $10 \mathrm{~Hz}$ ) filled with $2 \%(\mathrm{w} / \mathrm{v})$ Pontamine Sky Blue (PSB) in $0.5 \mathrm{M}$ sodium acetate solution and connected to a preamplifier (P16, Grass). Single-unit activity was visualized (signalto-noise ratio of at least $3: 1)$ on a digital storage oscilloscope (2211 Tektronix) as filtered (AC, bandpass $0.3-10 \mathrm{kHz}$ ) and unfiltered signals (DC) and listened to with an audiomonitor (AM8, Grass). The AC trace was used for the on-line count of action potentials with an amplitudesensitive spike discriminator (Neurolog Spike Trigger, Digitimer Ltd.). The unfiltered signal was used for on-line identification of the recorded neurons (spike shape and duration) and qualitative observations of possible alterations of spike waveform during pharmacological effects. Discriminator output pulses, analog signals proportional to the magnitudes of iontophoretic currents, as well as EEG and EMG recordings were collected on a computer via a CED interface using the Spike 2 software (Cambridge Electronic Design). To combine DRN single-unit recordings with microiontophoresis, a four-barrel micropipette (10-15 $\mu \mathrm{m}$ tip diameter) glued alongside the recording micropipette was used, as described previously (Akaoka et al., 1992). Each barrel was filled with one of the following solutions: 8-hydroxy-2-(Di- $n$-propylamino)-tetralin (8OH-DPAT, $10 \mathrm{~mm}, \mathrm{pH}$ 4; Sigma, L'Isle d'Abeau Chesnes, France), GABA (400 mM, $\mathrm{pH} 4$; Sigma), bicuculline methiodide ( $25 \mathrm{~mm}, \mathrm{pH} 4$; Sigma), and $\mathrm{NaCl} 0.9 \%$ (all drugs were dissolved in distilled water). Small negative retention currents $(2-5 \mathrm{nA})$ were used to avoid leakage of the active substances by diffusion. Current balancing techniques and current tests (Stone, 1985) were routinely performed via the salinecontaining barrel. Dorsal raphe serotonergic neurons were first localized using the DRN stereotaxic coordinates. The micropipettes with a $15^{\circ}$ caudorostral inclination were placed on the brain surface $4 \mathrm{~mm}$ posterior to the lambda, $0-0.4 \mathrm{~mm}$ lateral to the midline. DRN neurons were found $5800-6000 \mu \mathrm{m}$ below the brain surface. Neurons were identified as serotonergic if they met the criteria defined previously by McGinty and Harper (1976), Trulson and Jacobs (1979), and Levine and Jacobs (1992): i.e., (1) a slow and regular activity during quiet waking (1-4 Hz), (2) long-duration action potential ( $>2 \mathrm{msec}),(3)$ changes in activity directly correlated with changes in behavioral state, and (4) subsequent histological localization in the DRN.

Iontophoretic studies were conducted as follows. When a DRN unit was found, computer data collection was started, and a period of at least 2 min of spontaneous discharge was acquired before any drug application. For each neuron, one iontophoretic application of bicuculline (range 30-150 nA, 19-130 sec) was made. Bicuculline ejection was stopped at the beginning of the increase in firing judged by listening to the cell discharge and the increase of the impulse activity on the computer record. In some neurons, GABA was applied in a cyclic way using short-duration pulses $(3-5 \mathrm{sec})$. At the end of four to five consecutive daily recording sessions (4-6 hr each) on the same animal, PSB was deposited by iontophoresis in the same location as the last studied neurons $(50 \%$ duty cycle for $10 \mathrm{~min},-10 \mu \mathrm{A})$. The PSB deposit was then localized on $25 \mu \mathrm{m}$ sections obtained with a cryostat and stained with neutral red. In all rats, the PSB deposit was localized in the DRN, and no trace of the numerous tracks made with the micropipettes during the recording sessions was visible.

Data analysis. The firing rate of DRN neurons was analyzed off-line
Figure 1. Illustration of the activity of a DRN neuron during quiet waking $(W)$, slow-wave sleep $(S W S)$, and paradoxical sleep $(P S) . A$, The electromyogram $(E M G)$, the electroencephalogram $(E E G)$, the unit activity of the neuron, and its integrated firing rate (in Hertz) are displayed. Each vigilance state is discriminated with the EMG, the EEG, and its power spectrum $(B-D)$ in the lowfrequency range $(1.5-19 \mathrm{~Hz})$, and the highfrequency range $(19.5-50 \mathrm{~Hz})$ shown at higher gain. During W (characterized by a low-amplitude EEG and a sustained EMG activity with phasic bursts), the DRN neuron discharges tonically at $1.6 \mathrm{~Hz}$. During SWS [characterized by high-voltage spindles $(10-14 \mathrm{~Hz})$ and delta waves (1.5-4.0 $\mathrm{Hz}$ ) on the EEG and a low muscular activity], the DRN neuron progressively decreases its firing rate to $0.3 \mathrm{~Hz}$. During the subsequent PS episode [characterized by a desynchronized (activated) low-amplitude EEG with theta waves (5-9 Hz) and a flat EMG], the DRN neuron is virtually silent $(0.02 \mathrm{~Hz})$.
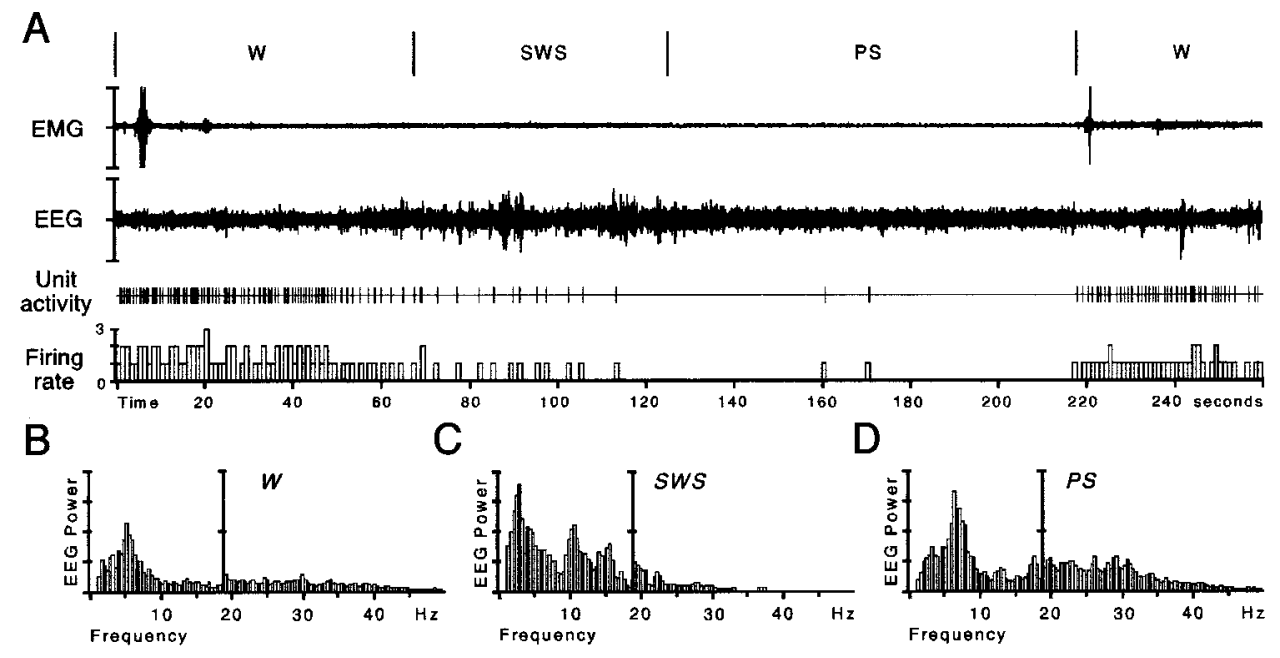
A

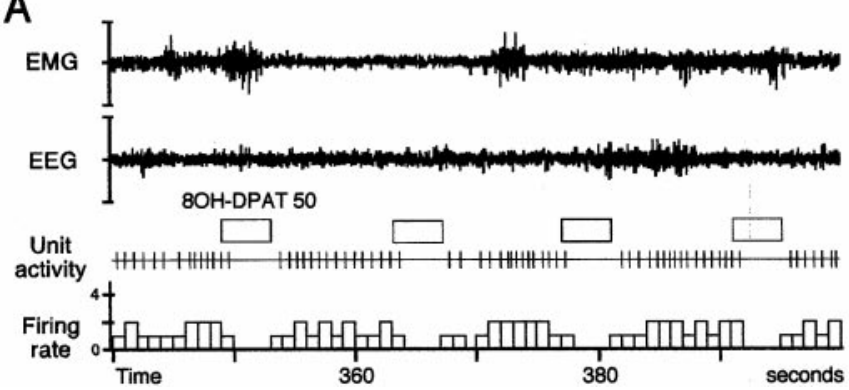

B

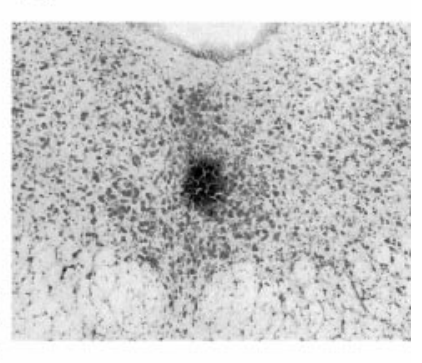

Figure 2. A, Effect of iontophoretic pulses $(50 \mathrm{nA}$, for $4 \mathrm{sec}$ every $14 \mathrm{sec})$ of $8 \mathrm{OH}-$ DPAT (a $5 \mathrm{HT}_{1 \mathrm{~A}}$ receptor agonist) on a DRN neuron during $\mathrm{W}$. The tonic activity of this neuron $(1.8 \mathrm{~Hz})$ is completely inhibited by $8 \mathrm{OH}$-DPAT applications. This result strongly suggests that the recorded neuron is serotonergic. $B$, Photomicrograph illustrating a small PSB deposit localized in the center of the DRN on a frontal section counterstained with neutral red. The PSB was iontophoretically applied $(-10 \mu \mathrm{A}, 10 \mathrm{~min})$ in the site in which neurons were recorded during the last day of experiments. It must be also noted that no lesion is visible in the DRN despite the multiple penetrations of the pipette assembly.

using Spike 2 software. All spike counts were taken from computer records of integrated impulse activity (1 sec bin width). Basal and post-drug firing rates were compared for periods matching for an equivalent behavioral state using polygraphic criteria and EEG spectral analysis. For each cell, the mean and SDs of basal firing rate were determined by averaging spike counts made for at least three separate $10 \mathrm{sec}$ epochs in one given vigilance state before bicuculline ejection. After the application of bicuculline, the discharge rate of the neurons quickly increased and then remained at an elevated stable value (plateau). The firing rate of the neurons during the effect was measured during the plateau phase. The onset of the plateau (latency, seconds) was defined as the time interval between the onset of the bicuculline application and the moment at which mean discharge value exceeded mean baseline activity by two SDs. The recovery time was defined as the time-interval between the offset of the ejection and the moment at which the firing rate had returned to a stationary level within two SDs of the baseline.

In a first group of neurons, the effect of bicuculline occurred during a continuous period of one of the three vigilance states. The mean discharge rate and SEM of these neurons in control conditions and under the bicuculline-induced plateau was calculated and compared using ANOVA and post hoc tests with the vigilance state as a factor. To take into account all variables, a multiple regression analysis (general linear model, Systat Software, SPSS) was performed with the bicucullineinduced increase of discharge, the latency or the recovery time as dependent variable, and the independent variables being either quantitative (intensity and duration of bicuculline applications) or qualitative (vigilance state).

For two other groups of neurons, the animals either displayed short successive periods of W and SWS (W-SWS transitions) or awoke from PS (PS-W transitions) during the plateau effect of bicuculline as defined above. For each of these neurons, we thus considered basal and plateau discharge rates for two behavioral states. The mean basal firing rate was calculated with the same method as for the first group (see above). The firing rate during the plateau effect of bicuculline was then calculated during periods of the same duration of either W and SWS or PS and W. The basal and post-drug mean firing rates during W and SWS on the one hand and PS and W on the other hand were then compared using ANOVA for repeated measures followed by Tukey's test for post hoc comparisons. The significance level for all statistical analyses was set at $p<0.05$. All data are expressed as mean \pm SEM.

\section{Retrograde tracing and immunohistochemistry of $G A D$}

The experimental protocol of the tract-tracing method has been described in detail in our previous papers (Luppi et al., 1990; Peyron et al., 1996, 1998). Briefly, male rats $(n=10,260-310 \mathrm{gm})$ were deeply anesthetized. A glass micropipette (3-5 $\mu \mathrm{m}$ tip diameter) filled with $1 \%$ CTb (List Biological Laboratories, Campbell, CA) solution [0.1 M phosphate buffer (PB), $\mathrm{pH}$ 6] was lowered into the DRN according to stereotaxic coordinates and extracellular recordings of the activity of serotonergic neurons (Aghajanian et al., 1972; Sprouse and Aghajanian, 1986). Then, the tracer was ejected iontophoretically by a $0.5-1.0 \mu \mathrm{A}$ pulsed positive current during a period of $10 \mathrm{~min}$. Five days later, $80 \mu \mathrm{g}$ of colchicine (Sigma) in $4 \mu \mathrm{l}$ of $\mathrm{NaCl} 0.9 \%$ was injected with a Hamilton syringe in one lateral ventricle. After $2 \mathrm{~d}$, the animals were perfused with a Ringer's lactate solution containing $0.1 \%$ heparine, followed by $500 \mathrm{ml}$ of a fixative composed of $4 \%$ paraformaldehyde and $0.2 \%$ picric acid in $\mathrm{PB}, \mathrm{pH}$ 7.4. The brains were post-fixed for $2 \mathrm{hr}$ in the same fixative at $4^{\circ} \mathrm{C}$.

Coronal sections $(20 \mu \mathrm{m})$ were then successively incubated in (1) a goat antiserum to $\mathrm{CTb}$ (1:40,000 with 2\% BSA; List Biological) over 3-4 $\mathrm{d}$ at $4^{\circ} \mathrm{C}$; (2) a biotinylated rabbit anti-goat IgG (1:2000; Vector Laboratories, Burlingame, CA) for $90 \mathrm{~min}$ at room temperature; and (3) an ABC-HRP solution (1:1000; Elite kit, Vector) for $90 \mathrm{~min}$ at room temperature. Then, the sections were immersed in a $0.05 \mathrm{M}$ Tris-HCl buffer, $\mathrm{pH}$ 7.6, containing 0.025\% 3,3'-diaminobenzidine-4 $\mathrm{HCl}$ (DAB; Sigma), $0.003 \% \mathrm{H}_{2} \mathrm{O}_{2}$, and $0.6 \%$ nickel ammonium sulfate for $15 \mathrm{~min}$ at room temperature. These $\mathrm{CTb}$-stained sections were further incubated in (1) a $3 \%$ swine serum for 90 min (Life Technologies, Rockville, MD), (2) a rabbit antiserum to GAD with $1 \%$ of swine serum over $3-4 \mathrm{~d}$ at $4^{\circ} \mathrm{C}$ (1:10,000; Chemicon International, Temecula, CA), (3) a donkey biotinylated anti-rabbit IgG (1:1000; Vector); and (4) ABC-HRP (1:1000; Elite kit, Vector), both for $90 \mathrm{~min}$ at room temperature. Finally, the sections were immersed for $15 \mathrm{~min}$ at room temperature in the same DAB solution as above without nickel. All incubations and rinses were made in KPBS $0.02 \mathrm{M}$ at $\mathrm{pH} 7.4$ except for the DAB. Controls in the absence of $\mathrm{CTb}$ or GAD antibodies and in the presence of BSA or swine serum, respectively, were routinely performed. On sections submitted to the double immunohistochemical procedure without the presence of $\mathrm{CTb}$ antiserum, no blue-black granular reaction product was visible, whereas on sections incubated without the GAD antibody, neurons with a cytoplasm labeled in brown could not be identified. Further supporting the specificity of our GAD immunostaining, singly CTb-labeled neurons did not display a brown coloration on double-stained sections, and the global distribution and the number of GAD-immunoreactive neurons were in
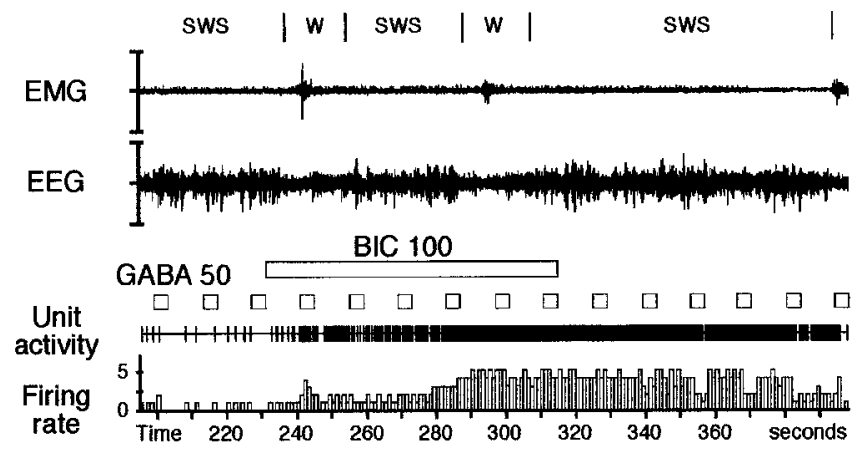

Figure 3. Effect of an iontophoretic application of bicuculline on a DRN serotonergic cell during successive short periods of $\mathrm{W}$ (microarousals) and SWS. In baseline conditions, the DRN neuron discharges at $0.3 \mathrm{~Hz}$ during SWS and $2.0 \mathrm{~Hz}$ during the first microarousal (at $240 \mathrm{sec}$ ). Forty-five seconds (at $278 \mathrm{sec}$ ) after the onset of the bicuculline application $(100 \mathrm{nA}, 59 \mathrm{sec})$, the neuron increases its discharge rate. Note that during the effect, the discharge rate of the neuron is similar during the short period of W $(4.9 \mathrm{~Hz})$ (at $300 \mathrm{sec})$ and the subsequent SWS $(4.8 \mathrm{~Hz})$. This indicates that GABA is responsible for the decrease of activity of the DRN serotonergic cells during SWS. The application of GABA $(50 \mathrm{nA}$, for $4 \mathrm{sec}$ every $14 \mathrm{sec}$ ) induced a complete cessation or a decrease of activity of the neuron before and during the beginning of the bicuculline application (up to $260 \mathrm{sec}$ ). During the remaining time of the application of bicuculline and up to $40 \mathrm{sec}$ after its cessation, GABA is no longer effective to induce an inhibition. The ability of GABA to decrease the firing of the cell reappeared at $356 \mathrm{sec}$. 
Table 1. Firing rates of DRN serotonergic neurons recorded in control conditions and during the effect of bicuculline

\begin{tabular}{|c|c|c|c|c|c|}
\hline \multirow[b]{2}{*}{ Vigilance state } & \multicolumn{3}{|c|}{ Mean discharge rate $(\mathrm{Hz})$} & \multicolumn{2}{|c|}{ Parameters of iontophoretic applications } \\
\hline & Baseline & Bicuculline & Increase of discharge ${ }^{a}$ & Current intensity (nA) & Ejection duration $(\mathrm{sec})$ \\
\hline W & $1.56 \pm 0.12^{b}$ & $\begin{array}{l}4.44 \pm 0.29^{* c} \\
(184 \%)^{d}\end{array}$ & $2.88 \pm 0.25^{c}$ & $80.0 \pm 4.4$ & $58.6 \pm 6.3$ \\
\hline SWS & $0.57 \pm 0.06^{b}$ & $\begin{array}{l}4.14 \pm 0.29^{* c} \\
(626 \%)^{d}\end{array}$ & $3.57 \pm 0.30^{c}$ & $88.7 \pm 4.1$ & $60.7 \pm 4.7$ \\
\hline PS & $0.06 \pm 0.02^{b}$ & $\begin{array}{l}4.22 \pm 0.36^{* c} \\
(6933 \%)^{d}\end{array}$ & $4.16 \pm 0.37^{c}$ & $106.9 \pm 8.2$ & $64.8 \pm 9.8$ \\
\hline
\end{tabular}

The increase of discharge, the intensity of current, and duration of the iontophoretic applications are summarized for each vigilance state.

${ }^{a}$ The increase of discharge corresponds to the discharge rate under bicuculline minus the discharge rate in baseline conditions.

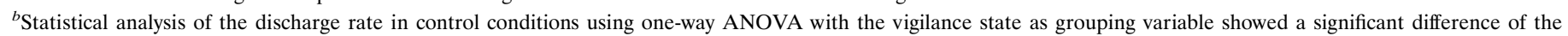
baseline firing rate between the three vigilance states $(p<0.001)$.

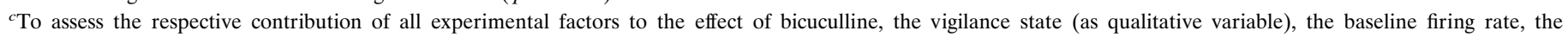

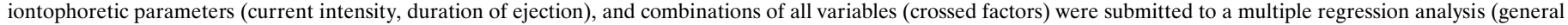
linear model). No significant difference in the firing rate under bicuculline between W, SWS, and PS was evidenced by this procedure.

${ }^{d}$ Average increase of the discharge rate expressed as a percentage.

*Value significantly different from baseline $(p<0.001)$.

line with previous studies (Mugnaini and Oertel, 1985; Ford et al., 1995). Section drawings were made with a Leitz Orthoplan microscope equipped with an $\mathrm{X} / \mathrm{Y}$ sensitive stage and a video camera connected to a computerized image analysis system (Biocom, Lyon, France). To precisely determine the respective contribution of each afferent to the GABAergic innervation of the DRN, we plotted and counted in three rats bilaterally retrogradely labeled $(\mathrm{CTb}+)$ and double-labeled $(\mathrm{CTb}+1$ $\mathrm{GAD}+$ ) cells on one section for each afferent structure. Numbers given in the text correspond to the mean number of $\mathrm{CTb}+/ \mathrm{GAD}+$ versus $\mathrm{CTb}+$ cells on one side of a section for a given structure.

\section{RESULTS}

\section{Neurochemical nature of the recorded neurons}

The single-unit activity of 85 neurons (from 15 rats) was studied during the iontophoretic application of bicuculline. These neurons were considered as being serotonergic neurons from the DRN based on the following criteria: (1) their long-duration action potential $(>2 \mathrm{msec})$, (2) a tonic discharge during W $(1.56 \pm 0.06 \mathrm{~Hz})$ and a decrease of activity during SWS $(0.50 \pm$ $0.05 \mathrm{~Hz}$ ) (Fig. 1), and (3) subsequent localization in the DRN by the PSB deposit. The PSB deposit made in the recording site for each rat the last day of recordings was in all cases localized in the DRN (Fig. 2).

In addition, 21 of these neurons (from eight rats) were recorded during a PS episode. They presented a mean discharge rate of $0.09 \pm 0.01 \mathrm{~Hz}$ during PS.

Thus, the neurons recorded in this study showed the same pattern of discharge across the sleep-waking cycle as that of DRN serotonergic neurons in cats (McGinty and Harper, 1976; Trulson and Jacobs, 1979; Levine and Jacobs, 1992).

The effect of an iontophoretically applied $5 \mathrm{HT}_{1 \mathrm{~A}}$ receptor agonist (8OH-DPAT) on neuronal activity during quiet $\mathrm{W}$ was also investigated on 37 of the recorded neurons (from 12 rats). The activity of all of these neurons was completely suppressed by 8OH-DPAT with ejection current of 40-65 nA during 4-5 sec (Fig. 2). The suppression of activity lasted for $5.4 \pm 0.9 \mathrm{sec}$. These results are similar to those reported for serotonergic neurons from the DRN recorded in anesthetized rats (Aghajanian et al., 1972; Sprouse and Aghajanian, 1986). Altogether, these results strongly support the serotonergic identity of the neurons recorded in the present study.

\section{Effect of GABA and bicuculline on DRN serotonergic neurons}

Iontophoretic applications of GABA were performed on 24 DRN serotonergic neurons (recorded from 11 animals) during quiet $\mathrm{W}$. Applications of GABA (30-60 nA, 3-5 sec) on these neurons completely inhibited their spontaneous activity. The application of bicuculline (60-100 nA, 22-94 sec) before GABA applications completely blocked the GABA-induced inhibitions on all neurons recorded (Fig. 3).

\section{Effect of bicuculline applications during W, SWS, or PS on DRN serotonergic neurons}

In a first group of 66 neurons, the effect of bicuculline occurred during one of the three vigilance states (Table 1). Iontophoretic application of bicuculline during W, SWS, or PS induced a progressive and sustained increase of the discharge rate of DRN neurons without inducing a change in the vigilance state. The firing rate significantly increased from $1.56 \pm 0.13$ to a plateau rate of $4.43 \pm 0.42 \mathrm{~Hz}$ ( $p<0.001$, Tukey's post hoc test) during quiet $\mathrm{W}$ ( $n=19$ neurons from eight animals) and from $0.57 \pm$ 0.08 to $4.14 \pm 0.48 \mathrm{~Hz}$ during SWS $(p<0.001)(n=34$ neurons

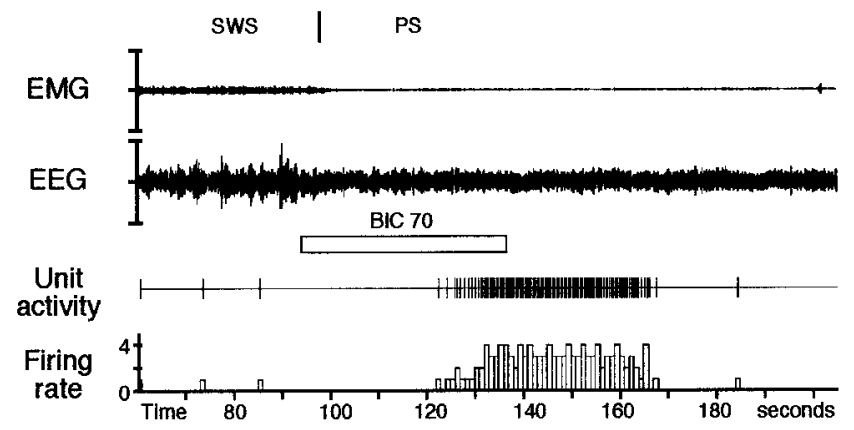

Figure 4. Effect of an iontophoretic application of bicuculline on a DRN serotonergic cell during PS. In control conditions, the DRN neuron does not discharge during PS $(100-120 \mathrm{sec})$. Thirty seconds after the onset of the bicuculline application $(70 \mathrm{nA}, 42 \mathrm{sec})$, the neuron increased its discharge rate to a mean frequency of $3.6 \mathrm{~Hz}$. The effect lasted $43 \mathrm{sec}$ and disappeared $31 \mathrm{sec}$ after the end of the bicuculline application. Note that the PS period is not disrupted by the application of bicuculline. 


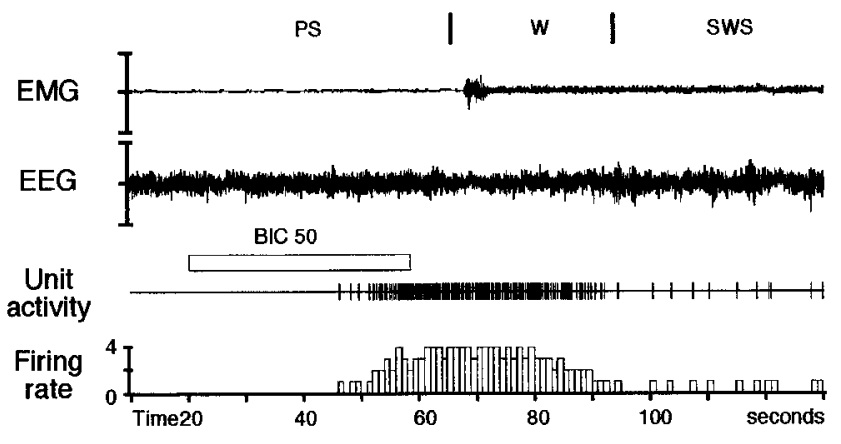

Figure 5. Effect of an iontophoretic application of bicuculline $(50 \mathrm{nA}, 38$ $\mathrm{sec})$ on a DRN neuron during a transition from PS to W. The effect of bicuculline started $28 \mathrm{sec}$ after the onset of the application (at $50 \mathrm{sec}$ ) and ceased $31 \mathrm{sec}$ after its offset. In control conditions, this DRN neuron fired at $1.3 \mathrm{~Hz}$ during $\mathrm{W}$ and was silent during PS. In contrast, under bicuculline, it presented a strong tonic discharge rate of similar value $(3.8 \mathrm{~Hz})$ during PS and the subsequent W. This result strongly suggests that the decrease of activity of DRN neurons during PS is mediated by GABA.

from nine animals). During PS, while DRN neurons were practically silent $(0.06 \pm 0.03 \mathrm{~Hz})$, they showed a remarkable increase of the firing rate to a plateau of $4.22 \pm 0.73 \mathrm{~Hz}(p<0.001)(n=$ 13 neurons from eight animals) after bicuculline application (Fig. 4). The latency for the appearance of the effect was of $58.61 \pm$ $6.31 \mathrm{sec}$ during W, $60.71 \pm 4.74 \mathrm{sec}$ during SWS, and $64.83 \pm 9.76$ sec during PS. The recovery time was $79.12 \pm 9.0 \mathrm{sec}$ for neurons recorded during $\mathrm{W}, 55.07 \pm 7.89 \mathrm{sec}$ for SWS neurons, and $30.83 \pm 7.21 \mathrm{sec}$ for neurons recorded during PS. Multiple linear regression analysis showed that the increased firing rate under bicuculline, the latency, and the recovery time were not statistically different between the three vigilance states $(p>0.05)$.

In a second group of 13 neurons (from five rats), the animals successively displayed short periods of W (microarousals) and SWS in control conditions and during the plateau effect of bicuculline. Although under control conditions these DRN neurons presented a statistically significant decrease $(p<0.001)$ in discharge rate during SWS $(0.58 \pm 0.07 \mathrm{~Hz})$ compared with microarousals $(1.53 \pm 0.13 \mathrm{~Hz})$, they showed under bicuculline virtually the same plateau rate during SWS and microarousals (4.55 \pm 0.38 and $4.74 \pm 0.38 \mathrm{~Hz}$, respectively) $(p=0.64$, Tukey's post hoc test) (Fig. 3).

In a third group of eight neurons (from four rats), the animals awoke from PS during the maximal effect of bicuculline. In baseline conditions, these neurons were nearly silent during PS $(0.08 \pm 0.05 \mathrm{~Hz})$ and had a tonic discharge rate during quiet $\mathrm{W}$ $(1.15 \pm 0.27 \mathrm{~Hz})(p<0.001)$. Under bicuculline (Fig. 5), their discharge rate was not significantly different between PS (4.65 \pm $1.18 \mathrm{~Hz})$ and the subsequent awakening $(4.93 \pm 0.91 \mathrm{~Hz})(p=$ 0.85, Tukey's post hoc test).

Finally, it should be noted that applications of 50-150 nA current $(25-73 \mathrm{sec})$ via the saline-filled barrel (current test) did not affect the spontaneous activity of DRN neurons whatever the vigilance state ( $n=10$ neurons from seven rats). In addition, in all cases the waveform characteristics of the recorded spikes were not modified during the application of bicuculline (Fig. 6).

\section{Origin of the GABAergic innervation of the DRN}

After CTb injections restricted to the DRN (Fig. 7A), the distribution of the retrogradely labeled cells was in agreement with our previous reports (Peyron et al., 1996, 1998). The largest number of retrogradely labeled cells immunoreactive to GAD $(\mathrm{CTb}+/$

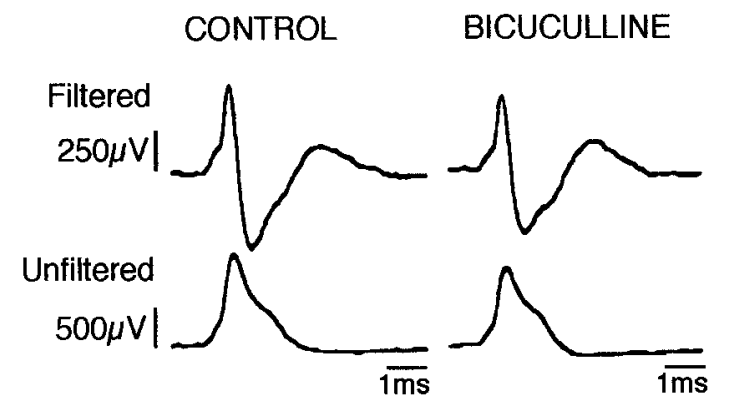

Figure 6. Raw electrophysiological waveforms of action potentials of a DRN neuron in control conditions and during the effect of an iontophoretic application of bicuculline $(70 \mathrm{nA}, 56 \mathrm{sec})$. The filtered (top traces, bandpass $0.3-3 \mathrm{kHz}$ on Grass P16 amplifier) as well as nonfiltered (bottom traces) traces clearly show the high signal-to-noise ratio of our recordings. The action potential is not significantly affected during the bicuculline effect, therefore ruling out possible artifacts. Note also the long duration of the action potentials typical of serotonergic neurons.

$\mathrm{GAD}+$ cells) was found in the lateral hypothalamic area (rostral part, $16 \mathrm{CTb}+/ \mathrm{GAD}+$ cells/32 CTb cells per section on one side, caudal part, 20/67) (Figs. 7C, 8B). A substantial number of double-labeled cells was also observed in the lateral preoptic area $(13 / 50)$ (Figs. $7 B, 8 A)$, the posterior hypothalamic area $(13 / 45)$, the substantia nigra reticular part (7/12 rostrally and 13/33 caudally), the ventral tegmental area (7/12) (Fig. 8C), the ventral pontine periaqueductal gray (Fig. $7 D$ ) including the DRN itself (5/27 rostrally and 10/28 caudally), and the rostral oral pontine reticular nucleus (7/38) (Fig. $8 D$ ). A moderate number of doublelabeled cells was seen in the ventral pallidum (4/10), the medial preoptic nucleus (5/9), the lateral parabrachial nucleus $(3 / 23)$ (Fig. 8E), and the dorsal paragigantocellular nucleus (3/7) (Fig. $8 F)$. Finally, a small number of $\mathrm{CTb}+/ \mathrm{GAD}+$ neurons was seen in the magnocellular preoptic nucleus $(2 / 5)$, the paraventricular hypothalamic nucleus $(2 / 4)$, the lateral habenula $(2 / 16)$, the tuberomamillary nucleus $(1 / 1)$, and the raphe magnus and gigantocellular $\alpha$ nuclei (1/2) (Fig. 8F).

\section{DISCUSSION}

In this report we show that when the GABAergic input to serotonergic neurons of the DRN is blocked during W, SWS, or PS by iontophoretic application of bicuculline, their discharge rate loses its relationship to the vigilance state. These results strongly suggest that GABA is responsible for the difference of activity of serotonergic neurons between W, SWS, and PS. This conclusion is strengthened by our results showing that when the effect of bicuculline occurred on neurons recorded at W-SWS or PS-W transitions, the difference in discharge rate between SWS and W (or PS and W) seen in control conditions was no longer visible. Indeed, if a neurotransmitter other than GABA was responsible for the decrease of activity of these cells during SWS and PS, it would still be active under bicuculline, and therefore a difference in discharge rate between W and SWS or W and PS should persist. This should be the case if the increase of activity seen in our experiments after ejections of bicuculline during SWS or PS was caused for example by unspecific effects, such as those reported in some in vitro studies (Heyer et al., 1982; Johnson and Seutin, 1997; Debarbieux et al., 1998). It might be also hypothesized that we applied too much bicuculline and therefore the increases of discharge rate that we saw could be caused by a disinhibition of excitatory interneurons within the DRN. We cannot rule out the possibility that such an indirect effect partic- 

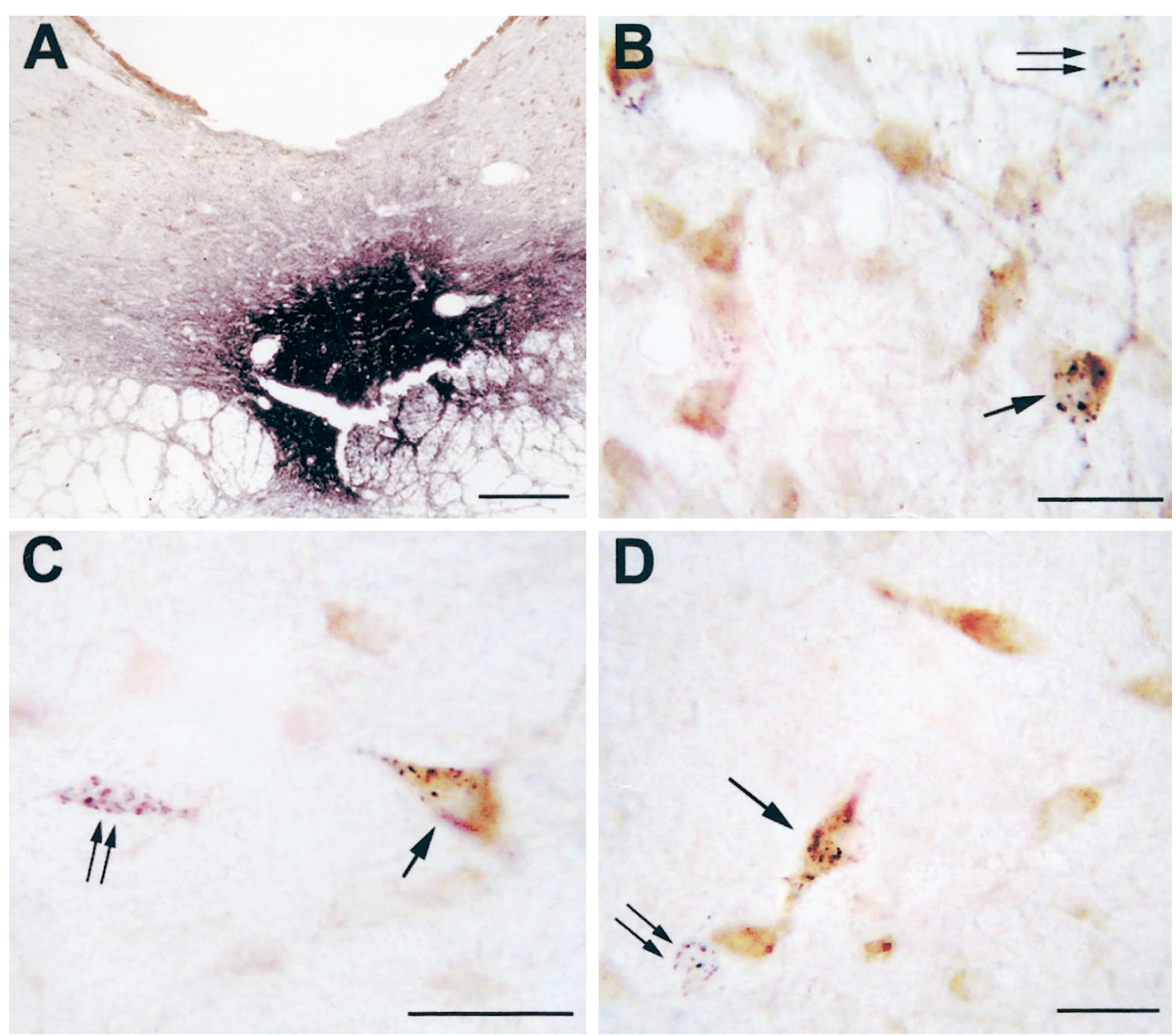

Figure 7. A, Photomicrograph illustrating a small CTb injection site limited to the ventral part of the DRN. Scale bar, $300 \mu \mathrm{m} . B-D$, Photomicrographs showing GAD (light brown) and CTb (black granules) double-labeled neurons (arrow), singly labeled GAD immunoreactive neurons, and singly CTb-labeled neurons (double arrow) in the lateral preoptic area $(B)$, the lateral hypothalamic area $(C)$, and the ventral periaqueductal gray $(D)$ after a $\mathrm{CTb}$ injection in the DRN. Scale bars, $25 \mu \mathrm{m}$. Note that the singly CTb-labeled cells display no brown coloration, indicating the absence of cross-reactivity between our two immunohistochemical reactions.

ipates in the increase of activity seen. However, it cannot explain the fact that when the plateau effect of bicuculline occurred on neurons recorded at W-SWS or PS-W transitions, they present the same tonic discharge rate across the different vigilance states in contrast to control conditions.

Our results are only partly in agreement with previous data. Indeed, Levine and Jacobs (1992) found in cats that the iontophoretic application of bicuculline on DRN serotonergic neurons during PS has no effect. The discrepancies between the two studies could be attributable to species differences. Indeed, presumed serotonergic neurons recorded in cats (Levine and Jacobs, 1992) have a discharge rate during $\mathrm{W}$ and SWS superior to that seen here in rats $(2.53 \mathrm{~Hz}$ vs $1.5 \mathrm{~Hz}$ and $1.49 \mathrm{~Hz}$ vs $0.5 \mathrm{~Hz})$, suggesting that the regulation processes might differ between the two species. In addition, Levine and Jacobs (1992) applied bicuculline on neurons during a continuous period of each of the vigilance states. Therefore, in contrast to us, they did not make the important observation that during W-SWS or PS-W transitions the difference of activity of a given DRN serotonergic neuron disappears under bicuculline. Finally, our results are strongly supported by results showing that a significant increase of the GABA release occurs in the cat DRN during PS as compared with SWS (Nitz and Siegel, 1997). In conclusion, our data and those of Nitz and Siegel (1997) strongly support the hypothesis that GABA is the only neurotransmitter responsible for the inactivation of the DRN serotonergic neurons during PS.

In addition, we and Levine and Jacobs (1992) found that the application of bicuculline during SWS restores a tonic firing in DRN serotonergic cells. These results indicate that an increase of the GABAergic inhibition of the DRN serotonergic neurons could be responsible for their decrease of activity during SWS. However, only a small nonsignificant decrease of the GABA release was observed with microdialysis in the DRN between W and SWS (Nitz and Siegel, 1997). Nevertheless, these authors made the following hypothesis to explain the discrepancy: "a small increase in the release of GABA possibly beyond the resolution of the microdialysis technique, might be sufficient to reduce DRN unit discharge in SWS."

Finally, our results, in contrast to those of Levine and Jacobs (1992), show that bicuculline application during W induces an increase in the activity of DRN serotonergic neurons. These results suggest the existence of a tonic GABAergic inhibition of the DRN serotonergic cells during quiet W. It would be interesting to determine whether this tonic inhibition decreases during active $\mathrm{W}$, during which in cats the serotonergic neurons of the DRN reach a discharge rate in the same range $(5.97 \mathrm{~Hz})$ as that 

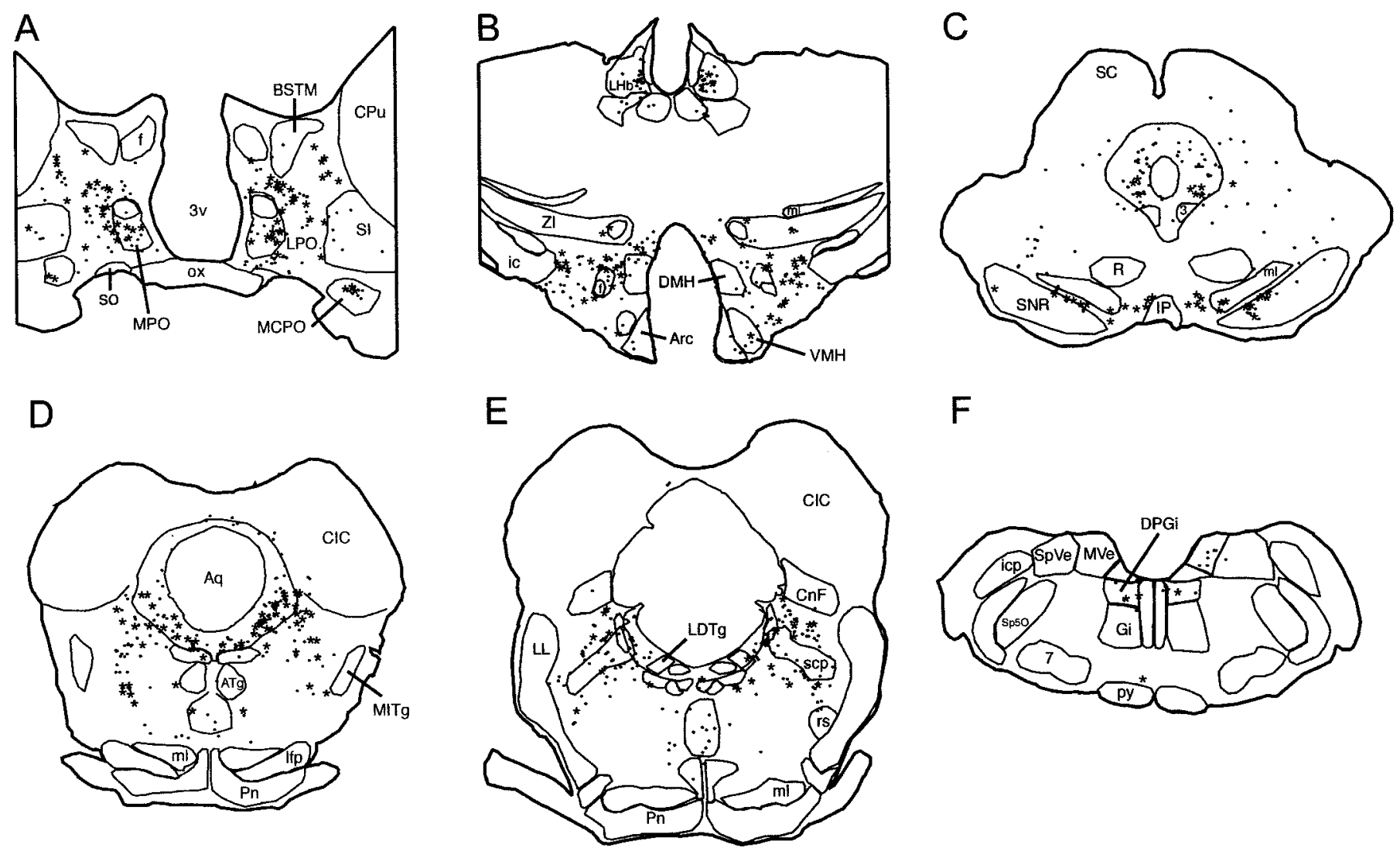

$\mathrm{F}$

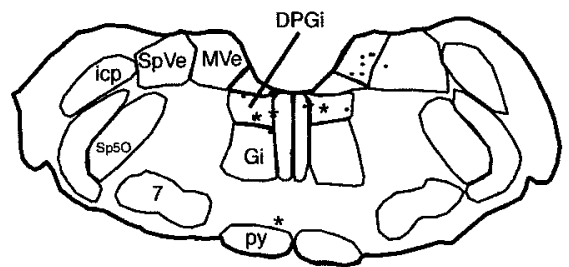

Figure 8. Schematic representation of the GABAergic afferents to the DRN from rostral to caudal levels. Drawings of $20 \mu \mathrm{m}$ frontal sections are shown. Each point corresponds to a retrogradely labeled cell $(\mathrm{CTb}+)$, and each star corresponds to a double-labeled cell $(\mathrm{CTb}+/ \mathrm{GAD}+)$. 3 , Oculomotor nucleus; 7, facial nucleus; $3 \mathrm{~V}$, third ventricle; $A r c$, arcuate nucleus; $A T g$, anterior tegmental nucleus; $A q$, aqueduct; $B S T M$, bed nucleus of the stria terminalis, medial division; $C I C$, central nucleus of the inferior colliculus; $C G$, central gray; $C N f$, cuneiform nucleus; $C P u$, caudate putamen; $D M H$, dorsomedial hypothalamic nucleus; $D P G i$, dorsal paragigantocellular nucleus; $f$, fornix; ic, internal capsule; icp, inferior cerebellar peduncle; $I P$, interpeduncular nucleus; $L D T g$, laterodorsal tegmental nucleus; lfp, longitudinal fasciculus of the pons; $L H b$, lateral habenular nucleus; $L L$, lateral lemniscus; $L P O$, lateral preoptic area; $m l$, medial lemniscus; $M C P O$, magnocellular preoptic nucleus; $M I T g$, microcellular tegmental nucleus; $M P O$, medial preoptic nucleus; $M V e$, medial vestibular nucleus; $o x$, optic chiasm; $P n$, pontine nuclei; $P y$, pyramidal tract, $R$, red nucleus; $r s$, rubrospinal tract; $S C$, superior colliculus; $s c p$, superior cerebellar peduncle; $S I$, substantia innominata; $S N R$, substantia nigra, reticulata; $S O$, supraoptic nucleus; $S p 5 O$, spinal 5 nucleus, oral part; $S p V e$, spinal vestibular nucleus; $Z I$, zona incerta.

seen under bicuculline (Trulson and Jacobs, 1979). The existence of such tonic inhibition during quiet $\mathrm{W}$ is supported by results showing that spontaneous GABA-mediated IPSPs occur in neurons from numerous brain structures in vitro (Otis et al., 1991; for review, see Mody et al., 1994). Furthermore, recent results showed that microdialysis of bicuculline in the DRN of unanesthetized rats during their active period (at night) is followed by a strong increase of the serotonin release in the DRN and the nucleus accumbens (Tao et al., 1996). We also recently provided evidence with the method used here that the noradrenergic cells from the locus coeruleus are also tonically inhibited by GABA during SWS, PS, and W (Gervasoni et al., 1998). Altogether these results suggest that many neurons from the CNS might be under a tonic GABAergic inhibition during the entire sleep-wake cycle.

In the second part of our study, we showed that the DRN receives GABAergic inputs from neurons located in a large number of distant regions from the forebrain to the medulla in addition to the local ventral pontine periaqueductal gray, including the DRN itself. It should be mentioned here that in our material, it was not possible to visualize the GABAergic neurons localized in the CTb injection site and its immediate surroundings. Although most GABAergic neurons localized in the DRN are concentrated more laterally than serotonergic neurons (Ford et al., 1995) and therefore are only partially masked by the sites, we might have underestimated the importance of their input. Our results nevertheless clearly show that GABA is not only contained in interneurons, in contrast to the classic concept. They greatly extend the notion (for review, see Ottersen et al., 1995) that long GABA projections are much more common than previously thought and that one population of neurons can be inhibited by several groups of GABAergic neurons located in different structures. They raise the question of the functional role of such complexity. One possibility is that some of these GABAergic afferents terminate on non-serotonergic neurons located in the DRN. In particular, they could terminate on GABAergic interneurons and be primarily involved in disinhibition of the serotonergic cells. However, Wang et al. (1992) have shown by electron microscopy that only a few GABAergic terminals contact nonserotonergic cells in the DRN. It is also possible that, as in other systems (Somogyi et al., 1998), GABAergic afferents are presynaptic and/or contact different parts of the serotonergic neurons, e.g., the cell body and different dendritic regions. Finally, it is likely that each GABAergic afferent is active under different physiological conditions. In particular, on the basis of our electrophysiological data, we expect that one or several of these GABAergic afferents are "turned on" or increase their activity 
selectively during SWS and PS and are responsible for the progressive decrease of activity of the DRN serotonergic neurons during these sleep states. Among the GABAergic structures revealed in our study, a few are good candidates for such roles.

The most likely candidates for the inhibition of the serotonergic DRN neurons during SWS are the GABAergic neurons distributed over the entire extent of the lateral preoptic area. A large number of studies indicate that the lateral preoptic area plays an important role in sleep onset and maintenance. For example, lesion of the lateral preoptic area induced insomnia, whereas its stimulation induced SWS (Sterman and Clemente, 1962; McGinty and Sterman, 1968; Lucas and Sterman, 1975; Sallanon et al., 1989; Asala et al., 1990; John et al., 1994). Neurons that increase their activity during sleep have been recorded in this area (Kaitin, 1984; Szymusiak and McGinty, 1986; Koyama and Hayaishi, 1994; Szymusiak et al., 1998). More recently, it has been shown that GABA or c-fos-positive neurons observed after long periods of sleep specifically in the ventrolateral preoptic area project to the tuberomamillary nucleus (Sherin et al., 1996, 1998). We also recently showed that noradrenergic cells from the locus coeruleus receive a GABAergic input specifically from the ventrolateral preoptic area (Peyron et al., 1995; Luppi et al., 1999) and are tonically inhibited by GABA during SWS (Gervasoni et al., 1998). From these results, it can be hypothesized that GABAergic neurons covering the entire lateral preoptic area might inhibit DRN serotonergic neurons during SWS. In contrast, the GABAergic neurons inhibiting the histaminergic and noradrenergic nuclei during this sleep state would be mainly localized in the ventrolateral preoptic area. Additional physiological studies are necessary to confirm these hypotheses.

The GABAergic afferents responsible for the inhibition of the serotonergic neurons of the DRN during PS should be located in the lower brainstem. Indeed, it has been shown in decerebrate animals that PS-like episodes are still associated with a cessation of activity of these neurons (Hoshino and Pompeiano, 1976). The GABAergic afferent from the ventral pontine periaqueductal gray, including the DRN itself, is the best candidate for such inhibition. This pathway has already been described on slices in which focal iontophoretic application of NMDA in the ventral periaqueductal gray, including the DRN, induced bicuculline sensitive IPSPs in DRN serotonergic neurons (Jolas and Aghajanian, 1997). Moreover, Aghajanian et al. (1978) recorded in anesthetized rats neurons in the DRN with a pattern of activity reciprocal to that of serotonergic neurons. Some non-serotonergic neurons recorded in the DRN across the sleep-wake cycle have been found to specifically increase their discharge rate during PS (Shima et al., 1986; Kocsis and Vertes, 1992). In addition, Yamuy et al. (1995) observed a large number of serotonergic negative-/ c-fos-positive cells in the DRN and lateral to it after a long period of PS obtained by pontine injection of carbachol. Maloney et al. (1999) recently saw after a PS rebound induced by deprivation an increase in the number of $c$-fos $+/ G A D+$ neurons in the periaqueductal gray and the DRN. In conclusion, our results and the results of others suggest that GABAergic neurons from the ventral pontine periaqueductal gray, including the DRN itself, might be responsible for the inhibition of DRN serotonergic neurons during REM sleep. Additional physiological studies are nevertheless needed to confirm this hypothesis.

In addition to the lateral preoptic area and the ventral pontine periaqueductal gray, we report that the DRN receives numerous other GABAergic afferents. Although they could also play a role in the inhibition of serotonergic neurons during sleep, to our knowledge no data are available to support this view. One possibility is that these structures are responsible for the tonic GABAergic inhibition that we found during W. In particular, the strong GABAergic projection from the lateral and posterior hypothalamic areas could play such role because they contain neurons specifically active during W (Vanni-Mercier et al., 1984).

In conclusion, our data indicate that an increase of a GABAergic inhibitory tone present during wakefulness is likely responsible for the decrease of activity of the dorsal raphe serotonergic cells during slow wave and paradoxical sleep. On the basis of our anatomical results, we further propose that GABAergic neurons located in the lateral preoptic area and the pontine ventral periaqueductal gray, including the DRN, could be responsible for this reduction of activity during slow wave and paradoxical sleep, respectively. Additional physiological experiments are now necessary to test these hypotheses.

\section{REFERENCES}

Aghajanian GK, Haigler HJ, Bloom FE (1972) Lysergic acid diethylamide and serotonin: direct actions on serotonin-containing neurons in rat brain. Life Sci 11:615-622.

Aghajanian GK, Wang RY, Baraban J (1978) Serotonergic and nonserotonergic neurons of the dorsal raphe: reciprocal changes in firing induced by peripheral nerve stimulation. Brain Res 153:169-175.

Akaoka H, Charlety PJ, Saunier CF, Buda M, Chouvet G (1992) Combining in vivo volume-controlled pressure microinjection with extracellular unit recording. J Neurosci Methods 42:119-129.

Asala SA, Okano Y, Honda K, Inoue S (1990) Effects of medial preoptic area lesions on sleep and wakefulness in unrestrained rats. Neurosci Lett 114:300-304.

Dahlström A, Fuxe K (1964) Evidence for the existence of monoaminecontaining neurons in the central nervous system. I. Demonstration in the cell bodies of brain stem neurons. Acta Physiol Scand [Suppl] 232:1-55.

Darracq L, Gervasoni D, Soulière F, Lin JS, Fort P, Chouvet G, Luppi PH (1996) Effect of strychnine on rat locus coeruleus neurons during sleep and wakefulness. NeuroReport 8:351-355.

Debarbieux F, Brunton J, Charpak S (1998) Effect of bicuculline on thalamic activity: a direct blockade of $\mathrm{I}_{\mathrm{AHP}}$ in reticularis neurons. J Neurophysiol 79:2911-2918.

Ford B, Holmes CJ, Mainville L, Jones BE (1995) GABAergic neurons in the rat pontomesencephalic tegmentum: codistribution with cholinergic and other tegmental neurons projecting to the posterior lateral hypothalamus. J Comp Neurol 363:177-196.

Gallager DW (1978) Benzodiazepines: potentiation of a GABA inhibitory response in the dorsal raphe nucleus. Eur J Pharmacol 49:133-143.

Gallager DW, Aghajanian GK (1976) Effect of antipsychotic drugs on the firing of dorsal raphe cells. II. Reversal by picrotoxin. Eur J Pharmacol 39:357-364.

Gao B, Fritschy JM, Benke D, Mohler H (1993) Neuron-specific expression of $\mathrm{GABA}_{\mathrm{A}}$-receptor subtypes: differential association of the $\alpha 1$ and $\alpha 3$-subunits with serotonergic and GABAergic neurons. Neuroscience 54:881-892.

Gervasoni D, Darracq L, Fort P, Soulière F, Chouvet G, Luppi PH (1998) Electrophysiological evidence that noradrenergic neurones of the rat locus coeruleus are tonically inhibited by GABA during sleep. Eur J Neurosci 10:964-970.

Heyer EJ, Nowak LM, MacDonald RL (1982) Membrane depolarization and prolongation of calcium-dependent action potentials of mouse neurons in cell culture by two convulsivants: bicuculline and penicillin. Brain Res 232:41-56.

Hoshino K, Pompeiano O (1976) Tonic inhibition of dorsal pontine neurons during the postural atonia produced by an anticholinesterase in the decerebrate cat. Arch Ital Biol 114:310-340.

Jacobs BL, Azmitia EC (1992) Structure and function of the brain serotonin system. Physiol Rev 72:165-229.

Jacobs BL, Wilkinson LO, Fornal CA (1990) The role of brain serotonin. A neurophysiologic perspective. Neuropsychopharmacology $3: 473-479$.

John J, Kumar VM, Gopinath G, Ramesh V, Mallick H (1994) Changes in sleep-wakefulness after kainic acid lesion of the preoptic area in rats. Jpn J Physiol 44:231-242. 
Johnson SW, Seutin V (1997) Bicuculline methiodide potentiates NMDA-dependent burst firing in dopamine neurons by blocking apamin-sensitive $\mathrm{Ca}^{2+}$-activated $\mathrm{K}^{+}$currents. Neurosci Lett 231:13-16.

Jolas T, Aghajanian GK (1997) Opioids suppress spontaneous and NMDA-induced inhibitory postsynaptic currents in the dorsal raphe nucleus of the rat in vitro. Brain Res 755:229-245.

Jouvet M (1972) The role of monoamines and acetylcholine-containing neurons in the regulation of the sleep. Ergeb Physiol 64:166-307.

Kaitin KI (1984) Preoptic area unit activity during sleep and wakefulness in the cat. Exp Neurol 83:347-357.

Kocsis B, Vertes RP (1992) Dorsal raphe neurons: synchronous discharge with the theta rhythm of the hippocampus in the freely behaving rat. J Neurophysiol 68:1463-1467.

Koyama Y, Hayaishi O (1994) Firing of neurons in the preoptic/anterior hypothalamic areas in rat: its possible involvement in slow wave sleep and paradoxical sleep. Neurosci Res 19:31-38.

Levine ES, Jacobs BL (1992) Neurochemical afferents controlling the activity of serotonergic neurons in the dorsal raphe nucleus: microiontophoretic studies in the awake cat. J Neurosci 12:4037-4044.

Lucas EA, Sterman MB (1975) Effect of a forebrain lesion on the polycyclic sleep wake patterns in the cat. Exp Neurol 46:368-388.

Luppi PH, Fort P, Jouvet M (1990) Iontophoretic application of unconjugated cholera toxin $\mathrm{B}$ subunit $\mathrm{CTb}$ combined with immunohistochemistry of neurochemical substances: a method for transmitter identification of retrogradely labeled neurons. Brain Res 534:209-224.

Luppi PH, Gervasoni D, Peyron C, Rampon C, Barbagli B, Boissard R, Fort P (1999) Norepinephrine and REM sleep. In: Rapid eye movement sleep (Mallick BN, Inoué S, eds), pp 107-122. New Delhi: Narosa Publishing House.

Maloney KJ, Mainville L, Jones BE (1999) Differential c-Fos expression in cholinergic, monoaminergic, and GABAergic cell groups of the pontomesencephalic tegmentum after paradoxical sleep deprivation and recovery. J Neurosci 19:3057-3072.

McGinty DJ, Harper RM (1976) Dorsal raphe neurons: depression of firing during sleep in cats. Brain Res 101:569-575.

McGinty DJ, Sterman MB (1968) Sleep suppression after basal forebrain lesions in the cat. Science 160:1253-1255.

Mody I, De Koninck Y, Otis TS, Soltesz I (1994) Bridging the cleft at GABA synapses in the brain. Trends Neurosci 17:517-525.

Mugnaini E, Oertel WH (1985) An atlas of the distribution of GABAergic neurons and terminals. In: Handbook of chemical neuroanatomy, Vol 4: GABA and neuropetides in the CNS, Part 1 (Bjorklund A, Hokfelt T, eds), pp 436-608. Amsterdam: Elsevier.

Nitz DA, Siegel JM (1997) Inhibitory amino acid neurotransmission in the dorsal raphe nucleus during sleep/wake states. Am J Physiol 273:R451-R454.

Otis TS, Staley KS, Mody I (1991) Perpetual inhibitory activity in mammalian brain slices generated by spontaneous GABA release. Brain Res 545:142-150.

Ottersen OP, Hjelle OP, Osen KK, Laake JH (1995) Amino acid transmitters. In: The rat nervous system, Ed 2(Paxinos G, ed), pp 1017-1036. San Diego: Academic.

Pan ZZ, Williams JT (1989) GABA- and glutamate-mediated synaptic potentials in rat dorsal raphe neurons in vitro. J Neurophysiol 61:719-726.
Peyron C, Luppi PH, Rampon C, Jouvet M (1995) Location of the GABA-ergic neurons projecting to the dorsal raphe nucleus and the locus coeruleus of the rat. Soc Neurosci Abstr 21:373.

Peyron C, Luppi PH, Fort P, Rampon C, Jouvet M (1996) Lower brainstem catecholamine afferents to the rat dorsal raphe nucleus. J Comp Neurol 364:402-413.

Peyron C, Petit JM, Rampon C, Jouvet M, Luppi PH (1998) Forebrain afferents to the rat dorsal raphe nucleus demonstrated by retrograde and anterograde tracing methods. Neuroscience 82:443-468.

Sallanon M, Denoyer M, Kitahama K, Aubert C, Gay N, Jouvet M (1989) Long lasting insomnia induced by preoptic neuron lesions and its transient reversal by muscimol injection into the posterior hypothalamus in the cat. Neuroscience 32:669-683.

Sherin JE, Shiromani PJ, McCarley RW, Saper CB (1996) Activation of ventrolateral preoptic neurons during sleep. Science 271:216-219.

Sherin JE, Elmquist JK, Torrealba F, Saper CB (1998) Innervation of histaminergic tuberomammillary neurons by GABAergic and galaninergic neurons in the ventrolateral preoptic nucleus of the rat. J Neurosci 18:4705-4721.

Shima K, Nakahama H, Yamamoto M (1986) Firing properties of two types of nucleus raphe dorsalis neurons during the sleep-waking cycle and their responses to sensory stimuli. Brain Res 399:317-326.

Somogyi P, Tamas G, Lujan R, Buhl EH (1998) Salient features of synaptic organisation in the cerebral cortex. Brain Res Rev 26:113-135.

Sprouse JS, Aghajanian GK (1986) (-)-Propranolol blocks the inhibition of serotonergic dorsal raphe cell firing by $5-\mathrm{HT}_{1 \mathrm{~A}}$ selective agonists. Eur J Pharmacol 128:295-298.

Sterman MB, Clemente CD (1962) Forebrain inhibitory mechanisms, sleep pattern induced by basal forebrain stimulation in behaving cat. Exp Neurol 6:103-117.

Stone TW (1985) Microiontophoresis and pressure ejection. In: Methods in the neurosciences (IBRO handbook series) (Smith AD, ed), pp 23-38. New York: Wiley.

Szymusiak R, McGinty DJ (1986) Sleep-related discharge in the basal forebrain of cats. Brain Res 370:82-92.

Szymusiak R, Alam N, Steininger TL, McGinty DJ (1998) Sleep-waking discharge patterns of ventrolateral preoptic/anterior hypothalamic neurons in rats. Brain Res 803:178-188.

Tao R, Ma Z, Auerbach SB (1996) Differential regulation of 5-hydroxytryptamine release by $\mathrm{GABA}_{\mathrm{A}}$ and $\mathrm{GABA}_{\mathrm{B}}$ receptors in midbrain raphe nuclei and forebrain of rats. $\mathrm{Br} \mathrm{J}$ Pharmacol 119:1375-1384.

Trulson ME, Jacobs BL (1979) Raphe unit activity in freely moving cats: correlation with level of behavioral arousal. Brain Res 163:135-150.

Vanni-Mercier G, Sakai K, Salvert D, Jouvet M (1984) Waking-state specific neurons in the caudal hypothalamus of the cat. C R Acad Sci (Paris) 298:195-200.

Wang QP, Ochiai H, Nakai Y (1992) GABA-ergic innervation of serotonergic neurons in the dorsal raphe nucleus of the rat studied by electron microscopy double immunostaining. Brain Res Bull 6:943-948.

Yamuy J, Sampagna S, Lopez-Rodriguez F, Luppi PH, Morales FR, Chase MH (1995) Fos and serotonin immunoreactivity in the raphe nuclei of the cat during carbachol-induced active sleep: a doublelabeling study. Neuroscience 67:211-233. 